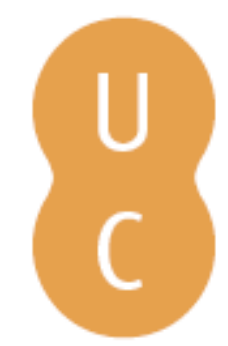

\title{
nommalina
}

\section{Adaptación de un tema clásico a una tendencia del teatro español del siglo XX: La Nieta de Fedra de Halma Angélico}
Autor(es):
López, Aurora
Publicado por: Centro de Estudos Clássicos e Humanísticos da Universidade de URL persistente: Coimbra; Imprensa da Universidade de Coimbra
DOI: $\quad$ DOI:http://dx.doi.org/10.14195/978-989-721-038-9_29
Accessed : $\quad$ 26-Apr-2023 10:02:44

A navegação consulta e descarregamento dos títulos inseridos nas Bibliotecas Digitais UC Digitalis, UC Pombalina e UC Impactum, pressupõem a aceitação plena e sem reservas dos Termos e Condições de Uso destas Bibliotecas Digitais, disponíveis em https://digitalis.uc.pt/pt-pt/termos.

Conforme exposto nos referidos Termos e Condições de Uso, o descarregamento de títulos de acesso restrito requer uma licença válida de autorização devendo o utilizador aceder ao(s) documento(s) a partir de um endereço de IP da instituição detentora da supramencionada licença.

Ao utilizador é apenas permitido o descarregamento para uso pessoal, pelo que o emprego do(s) título(s) descarregado(s) para outro fim, designadamente comercial, carece de autorização do respetivo autor ou editor da obra.

Na medida em que todas as obras da UC Digitalis se encontram protegidas pelo Código do Direito de Autor e Direitos Conexos e demais legislação aplicável, toda a cópia, parcial ou total, deste documento, nos casos em que é legalmente admitida, deverá conter ou fazer-se acompanhar por este aviso.

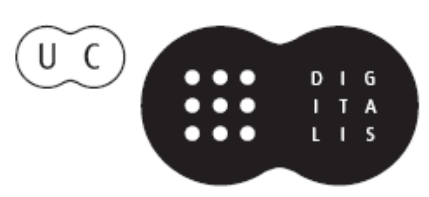




\section{De ayer a hoy}

\section{Influencias clásicas en la literatura}

\section{Aurora López, Andrés Pociña, Maria de Fátima Silva (coords.)}




\title{
AdAPTACión de un TEMA CLÁSICO A UNA TENDENCIA DEL TEATRO ESPAÑOL DEL SIGLO XX: LA NIETA DE FEDRA De Halma Angélico
}

Aurora López Universidad de Granada

\begin{abstract}
Dentro de las incontable reelaboraciones que se han realizado en el mundo moderno y contemporáneo del tema literario de Fedra e Hipólito, existe una muy interesante reescritura, apenas conocida y nunca estudiada con atención, titulada La Nieta de Fedra, publicada bajo el pseudónimo de Halma Angélico (Madrid, 1929), que corresponde a la escritora balear María Francisca Clar Margarit (Palma de Mallorca, 1880 - Madrid, 1952), curiosa y muy interesante dramaturga, perteneciente además a un tiempo en que eran muy escasas las mujeres que escribían teatro. Esta nueva versión del personaje de Fedra guarda una curiosa relación con la Fedra (1910) de Unamuno, y La malquerida (1913) de Benavente, aspecto que se contempla en este trabajo.
\end{abstract}

\section{Halma Angélico.}

Es necesario de vez en cuando recapacitar sobre el camino andado por las mujeres durante siglos, seguir manteniendo la llama encendida sin dejar de luchar para que no se extinga. Este lugar, Mar del Plata, tiene el poder del influjo y el peso de escritoras pioneras a las que personalmente admiro: Alfonsina Storni y las hermanas Victoria y Silvina Ocampo. A la memoria de las tres dedico esta investigación sobre una mujer poco conocida, autora teatral que ha ocupado un pequeño espacio en la dramaturgia de comienzos del siglo $\mathrm{XX}$ y que nos ofrece una reescritura del mito de Fedra en una de sus obras cuyo título es La nieta de Fedra.

Nuestra dramaturga, María Francisca Clar Margarit, que se esconde bajo el pseudónimo de Halma Angélico, nació en Palma de Mallorca en 1888, año natalicio igualmente de una gran luchadora por los derechos de la mujer, Clara Campoamor. Debido a que era hija de militar, vivió por algún tiempo en la isla filipina de Luzón, de la que su padre había sido nombrado gobernador. Después de la independencia de las Filipinas, en 1898, la familia se instala en Madrid, estudiando María Francisca en el Colegio del Sagrado Corazón.

La escritora se casa a la edad de 21 años y tiene dos hijos. Se sabe que se separó pronto de su marido y que se dedica a escribir cuentos y artículos de prensa en diarios como ABC, Heraldo, Blanco y Negro, y también en revistas femeninas, como Mujer y Mundo Femenino. 
Publica sus dos primeras obras teatrales en los años 1920 y 1922 bajo un pseudónimo distinto, Ana Ryus; eran sus títulos Los caminos de la vida (1920) y Berta (1922); la segunda de éstas se publicará de nuevo en 1929, esta vez con el título de La nieta de Fedra, adoptando entonces la autora el nuevo pseudónimo de Halma Angélico. En 1932 estrena en el Teatro Muñoz Seca de Madrid Entre la Cruz y el día, con la compañía de Margarita Robles y Gonzalo Degrás manteniéndose en cartel desde el 11 al 26 de junio.

En 1936 la Editorial Aguilar publica un volumen prologado por Cristóbal de Castro con el título Teatro de Mujeres, que contenía una selección de tres autoras Pilar Valderrama, Matilde Ras y Halma Angélico. La obra de nuestra autora que se edita lleva por título Al margen de la ciudad. Plantea en ella nuestra dramaturga el tema del deseo reprimido, al que pone cotos una educación determinada. Halma Angélico se opone a lo considerado moralmente correcto por la sociedad del momento, llegando al extremo de indicar en una acotación que una de las protagonistas saliese desnuda de una piscina; como era de esperar, tan censurable acción no llegó a producirse, entre otras razones porque la obra no se representó.

Finalmente el 25 de agosto de 1938 se estrena en el Teatro Español de Madrid $A K$ y la humanidad. La obra se basa en un cuento ruso y suscitó una auténtica guerra de los cenetistas contra nuestra autora, que pertenecía a dicho sindicato. La polémica se sustentó por una acusación de plagio del cuento de Jefin Sosulia. La consiguiente suspensión de la representación finalmente llevó a la autora a presentar su renuncia al Sindicato de Autores con la baja en dicho sindicato "por la campaña que la prensa confederal realiza contra su adaptación de $A K$ y la Humanidad". La guerra civil española llevó a la cárcel a la autora, por una duración de tres meses, bajo la acusación de republicanismo. Murió en Madrid el 9 de noviembre de $1952^{1}$.

Con estas pocas notas biográficas podemos imaginar la intensa actividad luchadora de nuestra autora, que fue precisamente la última presidenta de una institución que se preocupó por la formación feminista, el Lyceum Club. Perteneció además a la Asociación de Mujeres de España, de la que fue vicepresidenta en 1935, así como a la Unión de Mujeres de España.

\section{Algunas consideraciones sobre las mujeres y el teatro.}

La mitología clásica ha sido utilizada en la escritura de mujeres en todos los géneros literarios, logrando a través de distintas recreaciones o

${ }^{1}$ Los datos referentes a la vida de Halma Angélico, así como a sus publicaciones, los tomo fundamentalmente de la magnífica introducción de Fernando Doménech Rico, en AK y la Humanidad de Halma Angélico. Comedia inspirada en el cuento original del escritor ruso contemporáneo Jefin Sosulia (1938), Madrid, Publicaciones de la Asociación de Directores de Escena de España, 2001. 
transformaciones una propia expresión de sus propios yo y de los problemas sociales de su entorno. Por otra parte, dentro de la dramaturgia femenina, las obras del teatro greco-latino, portador de innovaciones del mito en los diversos autores y épocas, aportan no pocas reflexiones a las autoras y las empujan a realizar originales, en las que juega el deseo de presentar su propia autoridad en la creación.

Dentro de los géneros literarios cultivados por mujeres, el teatro, debido a múltiples factores derivados de la labor de los críticos, del desconocimiento y la opinión generalizada de que se trata de un género no adaptado a las mujeres..., también de la no menos problemática puesta en escena, ha sido el más tardío en poner de manifiesto la presencia de nombres de cultivadoras y de obras de creación teatral femenina. Sin embargo, una vez más la ausencia de las mujeres en este campo de la creación literaria no era tan absoluta y contundente como venía afirmándose; también aquí la labor de recuperación de autoras y de textos realizada en los últimos años por críticos y críticas feministas ha dado a luz a un alto número de autoras que cultivaron y cultivan diferentes modalidades teatrales ${ }^{2}$.

Dentro del panorama teatral español que media entre 1918 y 1936, la investigadora Pilar Nieva habla de 98 títulos de obras dramáticas que están firmados por 40 autoras y adaptadoras, recogidos en la prensa periódica. Dentro del grupo de autoras totalmente olvidadas la investigadora cita las siguientes: Pilar Algora, Halma Angélico, Adelina Aparicio y Osorio, Elena Arcediano, Carmen Baroja, Sofía Blasco, María Teresa Borragán, Adela Carbone, Carmen Díaz de Mendoza (Condesa de San Luís), María Luisa Madrona, Isabel Oyarzábal, Matilde Ras ${ }^{3}$. Estoy de acuerdo con la investigadora en que la situación social y política de la época es siempre necesaria para abordar las causas de este desajuste que, sin poder entrar en detalles, serían de forma esencial socialmente el bajo nivel educativo, que empieza a ser piedra de toque en los principios y actividades de la Institución Libre de Enseñanza, y a su lado una dependencia familiar de las mujeres, tanto de padres como de maridos,

${ }^{2}$ Por recordar algún ejemplo conspicuo, de notable interés resulta la labor realizada por Pilar Nieva de la Paz con la publicación Autoras dramáticas españolas entre 1918 y 1936, Madrid, CSIC, 1993; por su parte Juan Antonio Hormigón dirige la recopilación de datos sobre autoras desde el siglo XVI al XX en Autoras en la Historia del Teatro Español (1500-1994), vols. I y II, Madrid, ADE, 1996-1997. Labor muy destacada es la llevada a cabo por María José Ragué, no sólo con su fundamental monografía El teatro de fin de milenio en España (de 1975 hasta hoy), Barcelona, Ariel, 1996, sino con trabajos que interesan a la pervivencia del teatro antiguo, en los que tiene siempre presentes las reescrituras femeninas, como el ya clásico Lo que fue Troya. Los mitos griegos en el teatro español actual, Madrid, Asociación de Autores de Teatro, 1992 (sin olvidar que ella misma es muy interesante dramaturga, como puede comprobarse en creaciones como Lagartijas, gaviotas y mariposas (Lectura moderna del mito de Fedra), $\quad$ Murcia, Universidad, 1991.

${ }_{3}^{3}$ Pilar Nieva de la Paz, Autoras dramáticas españolas entre 1918 y 1936, cit., p. 63. 
siempre relegadas a un espacio privado que las elimina de la esfera política, sin tener siquiera acceso al voto.

La dedicación al teatro implica la necesidad de estrenar en locales comerciales, donde se contempla como elemento básico el éxito económico. No obstante nuestras autoras prescinden un tanto del aspecto comercial y presentan sus innovaciones, de corte un tanto feministas como La nieta de Fedra, en los llamados teatros de salón ${ }^{4}$, como el Teatro de la Escuela Nueva, fundado por Rivas Cherif en 1920, quien posteriormente fundó E1 Cántaro Roto (1927) y El Caracol (1928). Especial recuerdo merece aquí la fundación de un teatro-tertulia, llamado Fantasio, llevada a cabo por Pilar de Valderrama 5 .

\section{La nieta de Fedra.}

La obra que nos ocupa lleva en la portada, además del título y pseudónimo que ya conocemos, la leyenda "Teatro irrepresentable". Cuenta con un prólogo de Alejandro Bher, pseudónimo de María Valero de Mazas, seguido de otro prólogo de la autora. Está editada en Madrid, en los Talleres Tipográficos Velasco, Meléndez Valdés, 52, Año 1929.

El prólogolleva una cita de la propia Halma en modo alguno inconsecuente: "Si has sufrido mucho y luchado por vencerte..." Considera a la autora con talento, que escribe desde dentro afuera, dando a entender que la escritora no sigue preceptivas literarias específicas asimiladas sino que deja libertad a su creación y la considera una "pluma alta". Refiriéndose a la obra, remarca la personalidad de todos los personajes: la sirvienta vieja, los dos paletos, los dos seminaristas, la bruja, y los dos personajes femeninos centrales: Berta y su hija Ángela. De Berta el prólogo nos dice: "estatua viva de la soberbia castigada", de Ángela afirma que "sabe ser fuerte por el solo impulso del corazón”. Como punto final de este prólogo, quiero destacar la máscara lingüística con la que oculta su rostro la autora, utilizando un nombre de hombre para de este modo dar más autoridad y trascendencia al escrito.

Halma Angélico abriga el convencimiento de que ha escrito una obra con pocas posibilidades de representarse, teniendo más episodio narrativo que puramente teatral, con una preocupación de desvelar las causas que provocan las acciones de sus personajes. Sabe que cuenta con antecesores muy valorados, pero se anima a escribir también ella, hacerlo pensando quizá que no son mujeres las que hablan de sí mismas, sino hombres.

\footnotetext{
${ }^{4}$ Para una información más amplia cf. Pilar Nieva de la Paz, Op. cit., p. 168 ss., donde se estudian los teatros caseros y todo lo referente al mundo teatral de esos años.

${ }^{5}$ Mayor información en Shirley Mangini, Las modernas de Madrid, Barcelona, Ed. Península, 2001, pp.187-193, de gran interés por su atención a los hechos teatrales.
} 
Nos encontramos con la técnica propia del discurso femenino: en primer lugar, la llamada captatio benevolentiae de la retórica greco-latina, que en las escritoras tiende a ser una de las estrategias para hacerse escuchar, consistente en rebajarse ellas y poner como valiosos los escritos masculinos, entrando de puntillas en dicho espacio, aunque reafirmando su personalidad de mujer escritora. Así Halma ha jugado con un título que tuvo un espacio en el teatro greco-latino, Fedra, pero la reescritura del mito le hace pensar en otras anteriores, apelando a la autoridad masculina de dos grandes autores: Racine y Unamuno. El deseo de autoría se muestra en el título La nieta de Fedra, que explica muy bien todo lo dicho: "he querido nombrar mi obra de este modo por respeto a la valía del asunto, y, ya que varios maestros de la Literatura, entre ellos Racine y nuestro (sic) gran Unamuno sintieron la misma inquietud de trasladar a diferentes tiempos la misma complicación tejida de diferente modo, yo, respetando la altura de estos maestros, anonadada por su grandeza y mi pequeñez, no me atrevo a dar a mi humanizada Fedra (Berta en este caso), el nombre clásico, ni tampoco hurtárselo del todo con dudosa fidelidad”. E1 texto continúa queriendo darle a esta Fedra una filiación diferente a la clásica al definir al personaje "mi Berta, justamente castigada en su soberbia, lucha con una pasión semejante a la de aquella". Así ha introducido un motivo para lograr la atención del lector que la retórica clásica contemplaba para un tipo de exordio: un asunto nuevo. Finaliza la presentación con una consideración que es ni más ni menos que una justificación de la pervivencia y de recepción de un texto clásico: "Así me amparo en el escudo glorioso de un nombre consagrado, que, a través de los siglos, se sucede en el mundo literario en diferentes formas de concepción, con mayor o menor acierto, pero sin interrumpir su estela jamás, por ser tan fatídicamente humano".

La obra se desarrolla en dos espacios temporales con dos decorados distintos, que marcan la ambientación en la que se mueven personajes diferentes, manteniéndose solo dos, Berta y la criada Paula, en las tres "jornadas" en las que se divide la obra. Dichas "jornadas" se subdividen en diferentes escenas.

La primera "jornada" se desarrolla en el interior de una vivienda y sirve de introducción para presentar al personaje Berta desde el punto de vista de la educación recibida de su madre, Mónica, mujer soltera que ha ocultado a su hija no solo su procedencia, sino que ha urdido una mentira: su marido ha muerto. La madre ha mantenido una educación que pretende evitarle caer en su propio comportamiento y educa a su hija en la rigidez, en una moralidad cristiana, creando una persona carente de humanidad a la que ha procurado que no le falte nada. Hay que añadir que la propia madre es precisamente todo lo contrario, una mujer cariñosa que está pendiente de esa hija y que rechazó luego al hombre padre de la joven, afrontando un papel difícil en la sociedad en la que vive. 
Paula, que lleva como criada en la casa veinte años, es de la misma edad que Mónica y ha sido su apoyo, su confidente y en el momento ambas están preocupadas por Berta, que sale con un joven. A ello se une una enfermedad de corazón que padece Mónica, que es tratada por un médico amigo, quien conoce al joven que anda con Berta; el médico le ha explicado la situación de madre soltera de Mónica, cosa que no importa al joven, también médico, que alaba la decisión de Mónica de no querer casarse y "olvidarse de razones y perjuicios que la sociedad tiene en cuenta".

Mónica denuncia lo que conlleva ser mujer en circunstancias como las suyas, en el seno de una sociedad que se preocupa de las apariencias, el mal, lo feo antes que lo bello. Un diálogo posterior entre Berta y Mónica refleja la falta de consideración y un orgullo personal de una "doña perfecta" en la hija, refiriéndose en este caso a las prostitutas: "Toda mujer tiene un honor que defender; si no sabe hacerlo, no merece compasión sino desprecio".

El drama madre-hija llega a su punto álgido en la confesión de la madre y en la crueldad de la hija para con ella. Paula, la criada profetiza: "teme el castigo que merece tu soberbia"

En la segunda "jornada" han transcurrido 17 años, en los que Berta ha quedado viuda con una hija, Ángela, y se ha vuelto a casar con un viudo Martín Conde, que también tiene un hijo, Lorenzo; además, tienen también un hijo de ambos. Es ahora realmente cuando el tema Fedra comienza.

El decorado nos traslada a un vestíbulo de una casa de campo perteneciente a un hacendado, Martín Conde. Estamos ahora en ambientes rurales, en los que se desarrolla una sociedad que a la autora no le es ni mucho menos indiferente, pasando revisión a personajes que son tipologías, como los dos amigos Sebastián y Cosme, que rehúyen responsabilidades personales después de haberse divertido con una joven a la que uno de ellos ha dejado embarazada.

No queda excluido el clero, esta vez en formación, representado por Lorenzo y por Román, con maneras de pensar religiosamente diferentes, donde se intuye claramente en el último una gracia sarcástica que no deja de ser producto de su origen social bajo, que intenta paliar empleando un lenguaje cargado de frases latinas. Dicho personaje refleja a las mil maravillas la educación que recibían en el seminario los jóvenes con relación a las mujeres, consideradas como un peligro encasillándolas en dos tipos: ángel o demonio. Además utiliza lo que es un servicio a la sociedad como un medio para acceder a puestos de importancia, cosa que no alcanzarían por otras vías las clases bajas. Lorenzo, en cambio, refleja en todo la educación recibida, con una buena disposición que incluso le llevó a entrar en el seminario porque le gustaba a su madre.

Dentro de esta crítica religiosa no se excluye la de las órdenes religiosas femeninas, que no aceptan el ingreso en sus filas de mujeres que no vayan 
provistas de una buena dote. La figura que centraliza esta cuestión es María Misericordia, amiga de Ángela. La joven acude a Martín para que le ayude a solucionar un doble problema, la falta de dinero y todo el rechazo que provoca su condición de "inclusera", palabra utilizada por Román, que dice: "No tiene nombre y en muchos conventos no la quieren".

Para que no falte nada en el análisis crítico del panorama humano y social, el drama también plantea el problema de la emigración, causada por suprimir los grandes hacendados el arriendo de sus tierras a los que las cultivan, prefiriendo proceder a la venta de las mismas.

Llegamos así al tema Fedra cuyo hipotexto más próximo, recordando las afirmaciones del Prólogo, se encuentra en los dramas homónimos de Racine ${ }^{6}$ y Unamuno ${ }^{7}$. Parece claro que la $\mathrm{Fe} d r a$ de Racine es la base de la creación de la joven Ángela, la Aricia francesa con la que Racine puso ante el público una modernización hecha para una sociedad diferente, que busca divertirse y enredarse en líos amorosos, que se interesa por problemas sucesorios y por la guerra. Igualmente la irrupción de un triángulo amoroso es producto de esta misma sociedad. La Fedra de Racine siente el poder de los celos al mismo tiempo que el amor apasionado por Hipólito. Igualmente Berta sufre de celos más odiosos todavía porque es su hija Ángela ${ }^{8}$ el objeto de los mismos,

${ }^{6}$ De la abundante bibliografía existente sobre la Phèdre de Racine, de la que también yo me he ocupado en diversas ocasiones, quiero recordar aquí: ediciones: Oeuvres de Racine (con el título Phèdre et Hippolyte), Paris, C. Barbin - J. Ribou, 1676 ("achevé d' imprimer", marzo de 1677); Oeuvres de Racine (con el título Phèdre), Paris, C. Barbin - D. Thierry, 1687; trads. esps.: de R. Chacel, Madrid, Alfaguara, 1983; de M. D. Fernández Lladó, Madrid, Cátedra, 1999; Estreno: 1 de enero de 1677, Hôtel de Bourgone, París; A. W. Schlegel, Comparaison entre la Phèdre de Racine et celle d'Euripide, Paris, 1807; L. Goldmann, Jean Racine dramaturge, Paris, L'Arche, 1956; A. Niederst, Racine et la tragedie classique, Paris, P.U.F., 1978; A. López, "Amor y culpa en Fedra: Eurípides, Séneca, Racine", en A. Pociña - A. López, Fedras de ayer y de hoy..., cit., pp. 147-169; A. López, "Nuevo escándalo de Fedra en el París de 1677: el estreno de Phèdre et Hippolyte de Jean Racine et de Jacques Pradon", en A. Pociña - A. López, Fedras de ayer y de boy..., cit., pp. 323-335; etc.

${ }^{7}$ Primera edición en la Revista La Pluma (Madrid), 1921, núms. 8, 9 y 10; M. de Unamuno, Teatro completo. Prólogo, ed. y notas bibliográficas de M. García Blanco, Madrid, Aguilar, 1959; estreno, 25 de marzo de 1918, Teatro Ateneo de Madrid; traducida al it. por Gilberto Beccari, R. Carabba Editore, Lanciano, 1921. Entre la abundante bibliografía, cf. F. Lázaro Carreter, "El teatro de Unamuno", Cuads. de la Cátedra Miguel de Unamuno 7 (1956) 5-29; A. Franco, El teatro de Unamuno, Madrid, Ínsula, 1971; J. S. Lasso de la Vega, “Fedra' de Unamuno”, en De Sófocles a Brecht, Barcelona, Editorial Planeta, 1974, pp. 205-248; A. Pociña, "Seneca e le sue opere nel teatro spagnolo del XX secolo”, en I. Dionigi (ed.), Seneca nella coscienza dell'Europa, Milano, Mondadori, 1999, pp. 299-325; C. Morenilla, "La obsesión por Fedra de Unamuno (1912), Villalonga (1932) y Espriu (1978)”, en A. Pociña - A. López, Fedras de ayer y de hoy..., cit., pp. 435-480; etc.

8 Sólo conozco otro caso de reescritura del tema de Fedra en el que la protagonista tenga una hija que intervenga como personaje autónomo en el desarrollo de la obra: se trata, sorprendentemente, de Phaedra's Love (1996), de Sarah Kane, donde Fedra tiene una hija, Estrofa, que tiene un papel fundamental en el diálogo con su madre en la Escena 3. 
pues ama a Lorenzo y es correspondida. Además la solución final del drama difiere poderosamente en este hipotexto en que no existe la muerte física de la protagonista: Fedra es condenada a vivir por su marido, Martín, incapaz ella misma de darse muerte debido a sus problemas educacionales.

La nieta de Fedra se acerca a la de Unamuno en la composición del ambiente, rural en ambos casos, con ideas, creencias y perjuicios muy semejantes: curiosamente, tres años después de la composición de la Fedra unamuniana, se estrena en Madrid, el 12 de diciembre de 1913, La Malquerida de Jacinto Benavente, que también resulta en cierto modo una reescritura, desde luego más alejada, del problema amoroso familiar que sirve de núcleo a las versiones de Fedra. Descubrimos, pues, una tendencia a un tipo de drama rural, familiar, de costumbres, que subyace en la base de las tres obras que contemplamos, por orden cronológico la Fedra de Unamuno $(1910)^{9}$, La Malquerida de Jacinto Benavente $^{10}$ y La nieta de Fedra de Halma Angélico. Tanto Berta como la Fedra unamuniana y la Raimunda de Benavente se mueven constreñidas por su condición de amas de casa rurales, por la sociedad ancestral que las rodea, pero sobre todo por su férrea ideología cristiana, de la que no se había librado tampoco la Fedra de Racine, por más que el dramaturgo francés pretendió mantener su drama en el pasado clásico.

Ángela es el personaje modélico, capaz de salvar a su madre de una situación embarazosa en la que la pasión desenfrenada de Berta ha estallado dentro de un espacio escénico marcado con una iluminación baja. La contrafigura, Ángela se matiza siempre como comprensiva, alegre, amante de los libros, de la naturaleza, siempre dispuesta a ayudar. Se diría que es más hija de su abuela, Mónica, que de su madre, y ello se debe a la acción de su criada Paula, una "nodriza" clásica muy especial que sigue las líneas de cariño y ayuda marcadas por los cánones clásicos a esta figura de las tragedias.

Berta es un carácter seco, adusto, concentrado, con mucho genio, producto sin duda del orgullo de ser una mujer sin fisuras morales en su pasado, pero que sufre la derrota de no ser la que fue, de amar a quien no debe. Para matizar esta situación la autora rompe el silencio de ese amor furtivo recordando Ángela cómo encontró a su madre besando una antigua fotografía de Lorenzo

${ }_{9}^{9}$ Aunque no se estrena hasta 1918, y no se publica hasta 1921, la Fedra de Unamuno circula ya a finales de 1911, llegando una copia al actor Fernando Díaz de Mendoza, el marido de María Guerrero, y al hispanista italiano Gilberto Beccari, que la traducirá y publicará en italiano. Toda esta información aparece muy bien documentada en M. García Blanco, "Introducción” al vol. XII de las Obras completas de Unamuno, p. 57 ss.

${ }^{10}$ Es indudable que Benavente conocía por lo menos la existencia de la Fedra de Unamuno, todavía no estrenada ni publicada. Está documentada la antipatía que el filósofo sentía por Benavente y su teatro; sin embargo, no consiguió aquél que su Fedra protagonizada por la famosa María Guerrero, que en cambio llevó a escena La Malquerida poco después, en 1913, desempeñando el papel principal de Raimunda. 
de pequeño, que se parece al hermanito de ambos. La reacción inmediata es el enfurecimiento de Berta, que casi pega a su hija creyendo que pueda sospecharse algo de su pasión por el hijastro, aunque no es esta la intención de la joven. La utilización del parecido Teseo joven - Hipólito sigue perdurando a través de las reescrituras, ahora modernizado con ayuda de la fotografía.

En una situación de desespero se queda sola en escena hasta que aparece Paula, quien sabe lo que le está ocurriendo a Berta, llegando a hacerle confesar que lucha por dominarse y que vencerá. Se ha mostrado de nuevo el cariño de Paula por Berta, reproduciendo las diversas situaciones, presentes en tantos hipertextos, del diálogo en Fedra y la Nodriza.

Llegamos así a la "jornada" tercera. Lorenzo confiesa a su padre su deseo de no volver al seminario, hecho que agrada a Martín, y que trasmite a Berta, produciéndose en ella una reacción rara. Quedan en escena Lorenzo y Berta, quien se da cuenta del enamoramiento del joven hacia su hija. La confrontación juventud-madurez, diferencia de belleza, provoca una relajación peligrosa, contemplada por una mala mujer, Mela, que hará de mensajera del hecho y que conseguirá todavía una mayor preocupación en Berta. En la escena VII, motivada por la oscuridad, por la confusión de Lorenzo que piensa que es Ángela a la que se declara, se va rompiendo la contención y llega a la confesión apasionadamente, sin trabas. Ángela contempla el proceso y como siempre se dispone a ayudar fingiendo que lo que ha sucedido es una cuestión suya y así se lo trasmite a Lorenzo.

La venganza corre a cargo de Martín-Teseo, quien conoce todo el asunto e innova con una solución de estilo propio: da paso al matrimonio de los jóvenes y ordena que se besen. La reacción que esperaba Martín se produce y la acotación escénica habla por si misma: Berta, tremante, sintiendo renacer en ella la pasión con mayor fuerza, se revuelve como una leona. Berta confiesa su pasión y pide que la mate, negándose Martín a hacerlo para que vea la felicidad de la pareja, lanzándole la palabra que sabe la lastimará más: Ramera.

Localizaciones diferentes, ambientes diversos, innovaciones acordes con los tipos de sociedad, denuncias que se enmarcan en ellas, permanencia de un mito con reescrituras diversas que llega para dar a las autoras sus propias visiones.

Halma Ángélico deja parte de su legado como mujer en la conversación de los dos personajes femeninos que más le agradan: Ángela y Paula. Dan valor a las madres solteras que se ocupan de sus hijos, culpando a los hombres por el abandono. La soberbia, una socialización de la culpa incluyendo en ello la educación que lleva a demonizar a las mujeres cuando son capaces de matar a sus bebés, sin culpar a la propia sociedad por ello. 
Berta es producto de una educación, una víctima del orgullo de ser como es, que queda desamparada ante la noticia dada por su madre de que es hija natural, por lo que rechaza a su madre y provoca su muerte. Es en este punto necesario señalar lo poco interrelacionadas que están madres e hijas en las reescrituras del tema, puesto de relieve de una manera especial por Unamuno. Los componentes mentales de la mencionada sociedad provocan en la protagonista la desazón que supone la soledad al sentirse excluida de ella. Apasionada, como las Fedras de las que es hija, o nieta, se arma con una coraza propia, un carácter duro, que contrasta con el poco coraje de exigir al marido que la mate.

Como hemos visto en la referencia a las otras obras la autora siguió luchando para alcanzar metas de libertad en la sociedad.

Para terminar, diré que la autora ha sido muy inteligente al poner en la portada de su drama “Teatro Irrepresentable”, por ese afán de meticulosidad explicativa de las escenas, que contrasta con el ideal de su Fedra expresado por Miguel de Unamuno. 